\title{
THE EFFECT OF SUPERALLOY STRUCTURE ON ULTRASONIC WAVE PARAMETERS
}

\author{
Jacek Nawrocki ${ }^{1,(*)}$ \\ Kamil Gancarczyk ${ }^{2}$ \\ Wojciech Manaj ${ }^{3}$ \\ Robert Albrecht ${ }^{4}$ \\ Rafal Cygan $^{5}$ \\ Krzysztof Krupa ${ }^{1}$
${ }^{1}$ Research and Development Laboratory for Aerospace Materials, Rzeszow University of Technology, Poland
${ }^{2}$ Department of Material Science, Faculty of Mechanical Engineering and Aeronautics, Rzeszow University of Technology, Poland
${ }^{3}$ Institute of Aviation, Warsaw, Poland
${ }^{4}$ Institute of Materials Science, University of Silesia, Katowice, Poland
${ }^{5}$ Pratt \& Whitney Rzeszów” S.A, factory
${ }^{(*)}$ jaceknaw@prz.edu.pl

\begin{abstract}
This paper analyses the nickel based superalloy Inconel 713C casts typically used in high and low pressure turbines of aircraft engines. The ingots were manufactured in the Research and Development Laboratory for Aerospace Materials at the Rzeszów University of Technology. The superalloy structures were analysed by the following methods: $X$-ray diffraction orientation measurement and ultrasonic wave propagation. Ultrasonic techniques are mainly used to measure the blade wall's thickness. Measurement accuracy is determined by the velocity of the ultrasonic wave in the material tested. This work evaluates the effect of the nickel-based superalloy microstructure on the velocity of the ultrasonic wave propagation. Three different macrostructures: equiax (EQ), directionally solidified (DS) and single crystal (SX) were analysed. The authors determined the crystal misorientation in the obtained casts as the deviation of [001] crystallographic direction from the withdrawal axis or the main axis of the ingots. The measurements performed allowed researchers to identify significant differences in the wave velocity between EQ, DS and SX structures.
\end{abstract}

Keywords: ultrasonic nondestructive testing, superalloy, turbine blade, macrostructure, crystalline orientation.

\section{Highlights:}

- Evaluation of crystal perfection was based on the measurements of $\alpha$ angle - the angle between the crystallographic growth direction [001] and the main axis of the blade - $\mathrm{z}$.

- Single crystal was made by the Bridgman method at the withdrawal rate of $3 \mathrm{~mm} / \mathrm{min}$.

- The cross-sections of the samples of different microstructures were firstly characterized by the $\Omega$-scan technique to investigate the misorientation of grains on the surface.

- Substantial differences in the velocity and acoustic birefringence of the ultrasonic wave in different casting structures were studied. 


\section{INTRODUCTION}

Turbine blades rotate inside the engine at a speed up to $10000 \mathrm{rev} / \mathrm{min}$ and the tensile stress up to $300 \mathrm{MPa}$. The blades are manufactured using a precise casting method [1] with a specially designed geometry [2] responsible for the strength and proper cooling of blades during service. Despite very difficult work conditions in modern jet engines, engineers are forced to "slim" the blades' walls by reducing the blades' overall mass, which results in increasing load on the body section of a blade. However, the uniformity of the wall's thickness has to be controlled during the manufacturing process.

Among the non-destructive methods that can measure the wall's thickness: active thermography [3], X-ray tomography [4], eddy current [5], and the ultrasonic technique [6], the last one is the most commonly used. In this work, the ultrasonic technique was used for investigation. The ultrasonic technique is based on measuring transit and return time of the longitudinal and transverse waves reflected from the opposite side of the wall. Measured transition time is converted into the velocity of the wave in the material measured. The speed of transverse waves propagating in a thickness direction was measured at two mutually perpendicular positions of the ultrasonic probe, i.e. perpendicular each other polarization. In the tests, an ultrasonic probe with a frequency of $5 \mathrm{MHz}$ was used.

The value of birefringence is defined by the following relation:

$$
B=\frac{\left(V_{T 2}-V_{T 1}\right)}{0,5\left(V_{T 2}+V_{T 1}\right)}
$$

where $\mathrm{V}_{\mathrm{T} 1}, \mathrm{~V}_{\mathrm{T} 2}$ - velocity of transverse waves propagating in the direction of the sample's thickness and polarized in mutually perpendicular directions.

The waves's velocity is affected by the material's structure, presence of grain boundaries [7] and crystallographic orientation. In the research presented, the influence of three different microstructures: equiax grain (EQ), directionally solidified (DS) and single crystal (SX) on the waves' velocity was investigated.

\section{EXPERIMENTAL}

Cylindrical shape model samples were designed and manufactured to obtain different structures identical as turbine blades castings. Nickel base superalloy Inconel 713C was cast into ceramic shell moulds. Equiax samples were manufactured using Vacuum Induction Melting method (VIM), polycrystalline structure were obtained with modified surface of ceramic mould [8]. Direct solidified and single crystal samples were manufactured by Bridgman technique [9]. All process parameters are presented in Table 1.

Samples were etched to expose microstructure in a mixture of $\mathrm{HNO}_{3}(20 \mathrm{~g} / \mathrm{l}), \mathrm{HCl}(300 \mathrm{~g} / \mathrm{l})$, $\mathrm{FeCl}_{3}(160 \mathrm{~g} / \mathrm{l}), \mathrm{H}_{2} \mathrm{O}(100 \mathrm{ml} / \mathrm{l})$ at $50^{\circ} \mathrm{C}$, time of etching was $30-60$ seconds. Crystal orientation was measured using $\Omega$-scan technique on X-Ray OD EFG diffractometer [10]. With the use of diffractometer the angle between one of the main crystallographic direction $<001>$ and the direction normal to the sample surface were measured. Source of radiation $\mathrm{Cu}_{\mathrm{K \alpha}}=0.1542 \mathrm{~nm}$ was used. The diffractometer is able to map the surface sample with a single measurement point about $0.8 \mathrm{~mm}$. Samples of $10 \mathrm{~mm}$ length were measured to evaluate velocity of longitudinal and transverse waves using $5 \mathrm{MHz}$ transducers. 
Table 1. Solidification process parameters

\begin{tabular}{|c|c|c|c|}
\hline Casting Type & $\begin{array}{c}\text { Mould Temperature } \\
{ }^{\mathbf{C}} \mathbf{C}\end{array}$ & $\begin{array}{c}\text { Alloy Temperature } \\
{ }^{\mathbf{O}} \mathbf{C}\end{array}$ & $\begin{array}{c}\text { Withdrawal rate } \\
\mathbf{m m} / \mathbf{m i n}\end{array}$ \\
\hline Equiax & 1100 & 1470 & - \\
\hline Direct Solidify & 1500 & 1520 & 4.0 \\
\hline Single Crystal & 1500 & 1520 & 3.0 \\
\hline
\end{tabular}

\section{RESULTS}

The cross-sections of the samples obtained with different microstructure were firstly characterized by the $\Omega$-scan technique to investigate the misorientation of the grains on the surface. Figure 1 presents the maps of misorientation from the samples' surfaces obtained by different solidification techniques. Samples of the equiaxed grains' structure were not fully characterized due to the fact that the beam diameter covered multiple oriented grains. The diffractometer software was not able to distinguish multiple orientations from more than one grain. Grains size varied from 0.5 to $2 \mathrm{~mm}$ while the alpha angle from 4 to 45 degrees. The directionally solidified cast revealed few grains on the measured surface whose alpha angle varied from 5 to 50 degrees. The single-crystal sample had a single grain with misorientation of about 1 degree and deviation of [010] direction from the sample axis equal to about 21 degrees. Figure 2 shows the microstructure of the samples obtained.

a)

Value of alpha angle, deg
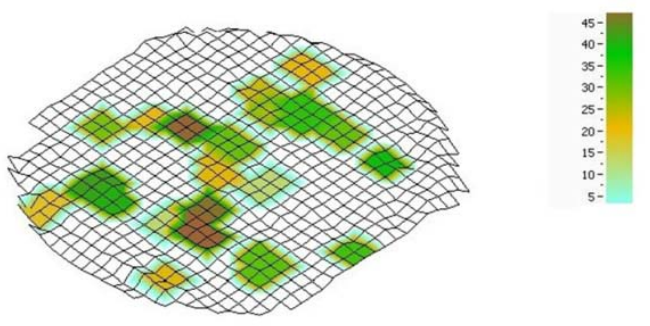

b)

Value of alpha angle, deg
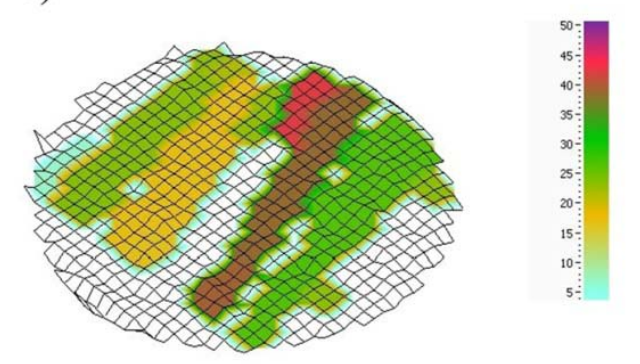

c)

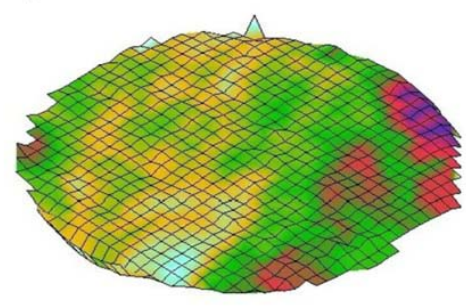

Value of alpha angle, deg

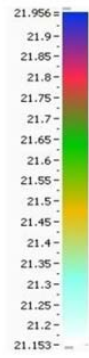

Figure 1. The distribution of the angle value: a) equiax, b) directionally solidified, $c$ ) single crystal 

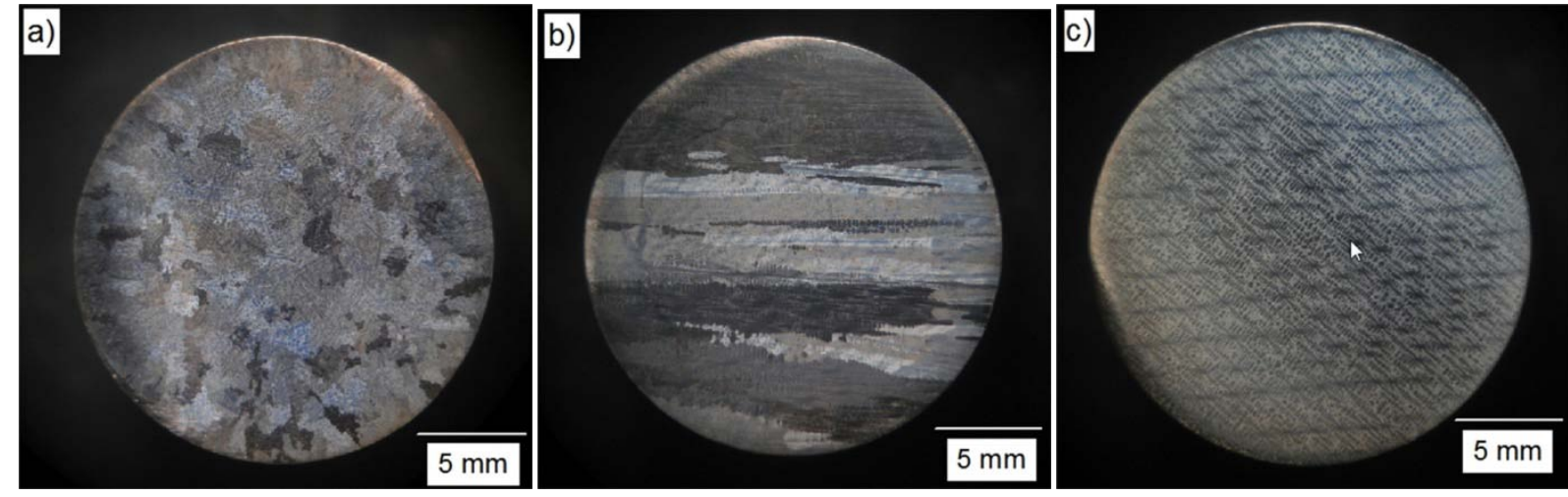

Figure 2. Macrostructure: a) equiax, b) direct solidify, c) single crystal

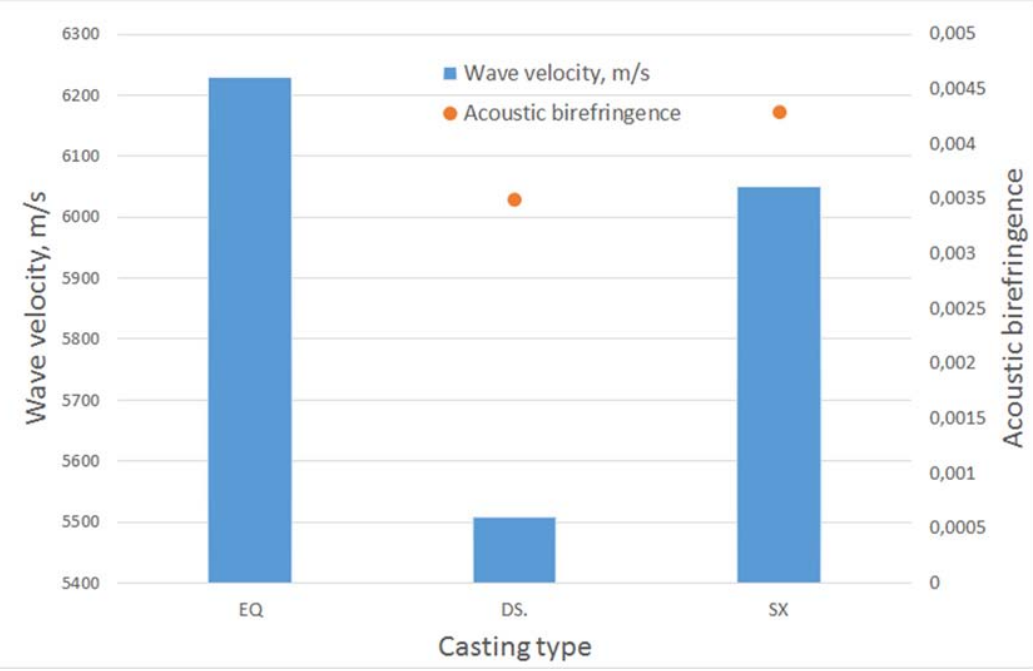

Figure 3. Velocity of ultrasonic waves and acoustic birefringence in equiaxed, directionally solidified and single-crystal structures

\section{CONCLUSIONS}

This study shows that there are substantial differences in ultrasonic wave velocity and acoustic birefringence between different casting structures. Ultrasonic waves propagate fastest in the DS casting in [010] direction and are about 5\% faster than the waves velocity in the EQ casting. The slowest longitudinal waves velocity propagation occurs in the SX casting in [010] direction. The difference between the DS and SX casting exceeds $500 \mathrm{~m} / \mathrm{s}$ (8\%). Taking this into consideration, the wall thickness evaluation should be preceded by the material structure analysis to prevent the measurement system from potential failure during calibration. Calibration plates for thickness measurement should be manufactured from a material which has the same chemical composition and similar material structure. The acoustic birefringence difference between the DS and SX casting exceeds $17 \%$. The attenuation of transverse waves makes it impossible to obtain acoustic birefringence for the EQ casting. It gives the chance to develop a rapid method of type casting structure verification.

\section{ACKNOWLEDGEMENTS}

The authors gratefully acknowledge the funding of the Polish National Centre for Research and Development. The project was realized within the frames of the Program DEMONSTRATOR PLUS UOD-DEM-1-557/001. 


\section{REFERENCES}

[1] Sims, C.T., Stoloff, N.S., Hagel, W.C. (1987). Superalloys II. A Wiley-Interscience Publication John Wiley \& Sons.

[2] Reed R. C. (2006). The Superalloys. Fundaments and Application. Cambridge University Press.

[3] Carl, V., Becker, E., Sperling, A. (1998). Thermography inspection system for gas turbine blades. Proceedings 7th European Conference on NDT. Copenhagen, p. 2658-2665.

[4] Kilian, D. (1999). 3D tomography of turbine blades. Proceedings of the International Symposium of Computerized Tomography for Industrial Applications. Berlin, 31, p. 1-17.

[5] Le Bihan, Y., Joubert, P-Y., Placko, D. (2001). Wall thickness evaluation of single crystal hollow blades by eddy current sensor. ND\&E International. 34, p. 363-368.

[6] Lane, C. (2014). The Development of a2D Ultrasonic Array Inspection for Single Crystal Turbine Blades. Springer Theses. Springer International Publishing. Switzerland, p. 63-79.

[7] Rinkevich, A. B., Stepanova, N.N., Rodinov D.P., Perov, D.V. (2009). Ultrasonic Testing of Single- and Polycrystal Articles Made of Nickel-Based Heat-Resistant Alloys. Russian Journal of Nondestructive Testing, vol. 45, no. 11, p. 3-21.

[8] Zielińska, M., Sieniawski, J., Poreba, M. (2007). Microstructure and mechanical properties of high temperature creep resisting superalloy René 77 modified CoAl2O4. Archives of Materials Science and Engineering, vol. 28, no. 10, p. 629-632. 